\title{
Alphabetisches Verzeichnis
}

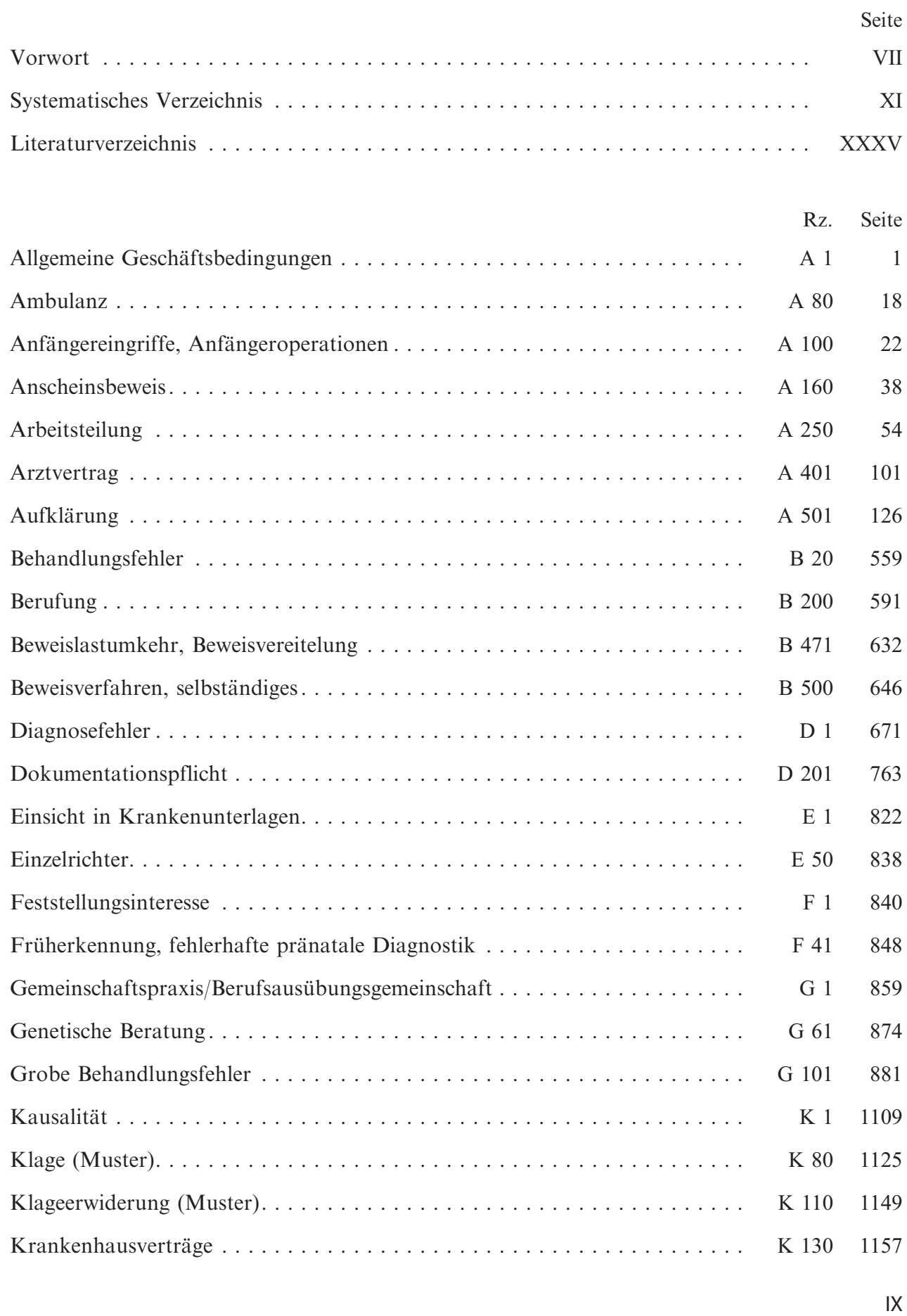

MWA6 - Druckdatei 
Alphabetisches Verzeichnis

\begin{tabular}{|c|c|c|}
\hline & Rz. & Seite \\
\hline Mitverschulden des Patienten & M 1 & 1182 \\
\hline Nichterkennen einer Schwangerschaft. & $\mathrm{N} 1$ & 1191 \\
\hline Patientenrechtegesetz & P 1 & 1193 \\
\hline Rückerstattung des Honorars $\ldots \ldots \ldots \ldots \ldots \ldots \ldots \ldots \ldots \ldots \ldots \ldots \ldots \ldots \ldots$ & R 1 & 1226 \\
\hline Sachverständigenbeweis. & S 1 & 1252 \\
\hline Schwangerschaftsabbruch, fehlerhafter . . . . . . . & S 200 & 1316 \\
\hline Sterilisation, fehlerhafte . & S 300 & 1333 \\
\hline Sturz im Pflegeheim und im Krankenhaus $\ldots \ldots \ldots \ldots \ldots \ldots$ & S 500 & 1342 \\
\hline Substantiierung der Klage/Schlüssigkeit & S 600 & 1365 \\
\hline Suizidgefährdete Patienten. . . . . . . . . . . . & S 630 & 1374 \\
\hline 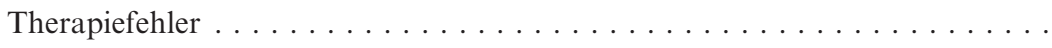 & $\mathrm{T} 1$ & 1381 \\
\hline Unterlassene Befunderhebung & U 1 & 1422 \\
\hline Verjährung . & $\mathrm{V} 1$ & 1561 \\
\hline Voll beherrschbare Risiken & V 301 & 1605 \\
\hline Zahnarzthaftung & $Z_{1}$ & 1645 \\
\hline
\end{tabular}

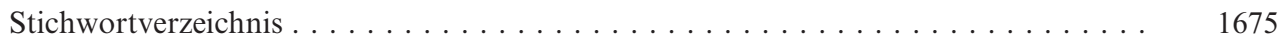

